\title{
Polímeros Sintéticos Biodegradáveis: Matérias-primas e Métodos de Produção de Micropartículas para uso em Drug Delivery e Liberação Controlada
}

\author{
Patrícia Severino \\ Departamento de Processos Biotecnológicos - UNICAMP \\ Faculdade de Ciências da Saúde - FCS-UFP \\ Maria Helena A. Santana \\ Departamento de Processos Biotecnológicos - UNICAMP \\ Samantha C. Pinho \\ Departamento de Engenharia de Alimentos - USP \\ Eliana B. Souto \\ Faculdade de Ciências da Saúde, UFP \\ Centro de Genómica e Biotecnologia - IBB/CGB-UTAD
}

\begin{abstract}
Resumo: Micropartículas produzidas a partir de polímeros sintéticos têm sido amplamente utilizadas na área farmacêutica para encapsulação de princípios ativos. Essas micropartículas apresentam as vantagens de proteção do princípio ativo, mucoadesão e gastrorresistência, melhor biodisponibilidade e maior adesão do paciente ao tratamento. Além disso, utiliza menores quantidade de princípio ativo para obtenção do efeito terapêutico proporcionando diminuição dos efeitos adversos locais, sistêmicos e menor toxidade. Os polímeros sintéticos empregados na produção das micropartículas são classificados biodegradáveis ou não biodegradáveis, sendo os biodegradáveis mais utilizados por não necessitam ser removidos cirurgicamente após o término de sua ação. A produção das micropartículas poliméricas sintéticas para encapsulação tanto de ativos hidrofílicos quanto hidrofóbicos pode ser emulsificação por extração e/ou evaporação do solvente; coacervação; métodos mecânicos e estão revisados neste artigo evidenciando as vantagens, desvantagens e viabilidade de cada metodologia. A escolha da metodologia e do polímero sintético a serem empregados na produção desse sistema dependem da aplicação terapêutica requerida, bem como a simplicidade, reprodutibilidade e factibilidade do aumento de escala da produção.
\end{abstract}

Palavras-chave: Polímeros, micropartículas, liberação controlada, métodos de produção.

\section{Biodegradable Synthetic Polymers: Raw-Materials and Production Methods of Microparticles for Drug Delivery and Controlled Release}

\begin{abstract}
Microparticles produced from synthetic polymers have been widely used in the pharmaceutical field for encapsulation of drugs. These microparticles show several advantages such as drug protection, mucoadhesion, gastro-resistance, improved bioavailability and increased patient's compliance. In addition, it is possible to use lower amount of drug to achieve therapeutic efficiency with reduced local/ systemic adverse side effects and low toxicity. Synthetic polymers used for the production of microparticles are classified as biodegradable or non-biodegradable, being the former more popular since these do not need to be removed after drug release. Production of polymeric microparticles can be used for encapsulation of hydrophilic and hydrophobic drugs, by emulsification following solvent extraction/ evaporation, coacervation, methods that are revised in this paper, including advantages, disadvantages and viability of each methodology. Selection of methodology and synthetic polymer depends of the therapeutic purpose, as well as simplicity, reproducibility and possibility to scale up.
\end{abstract}

Keywords: Polymers, microparticles, controlled release, production processes.

\section{Introdução}

Polímeros sintéticos têm sido amplamente empregados para a produção de micropartículas de estrutura matricial (microesferas) ou vesicular (microcápsula) para veiculação de fármacos, proteínas e peptídeos ${ }^{[1]}$. As vantagens obtidas com o uso das micropartículas poliméricas sintéticas são proteção do princípio ativo ${ }^{[2]}$, mucoadesão ${ }^{[3-5]}$; gastrorresistencia $^{[5]}$; reprodutibilidade e o fracionamento da dose $\mathrm{e}^{[6]}$ apresentando-se como fatores responsáveis para melhorar a biodisponibilidade dos fármacos ${ }^{[7,8]}$. e consequentemente, promovendo maior adesão do paciente ao tratamento.

O emprego de menores quantidade de menores quantidades de princípio ativo para obtenção do efeito terapêutico em conjunto com a liberação controlada proporcionam diminuição dos efeitos adversos locais, sistêmicos e menor toxidade ${ }^{[9]}$.

Vários polímeros sintéticos podem ser utilizados na produção de micropartículas e sua escolha depende da aplicação terapêutica requerida. Ao eleger o material a ser utilizado deve-se observar as características físico-químicas, como a viscosidade e a higroscopicidade ${ }^{[10-12]}$. Além disso, o polímero sintético deve ser biocompatível e ter capacidade de liberar completamente o solvente ou outros materiais utilizados durante o processo de encapsulação, além de não apresentar sabor desagradável no caso de consumo oral ${ }^{[13]}$.

Autor para correspondência: Eliana B. Souto, Faculdade de Ciências da Saúde, Universidade Fernando Pessoa, Rua Carlos da Maia, 296, CEP 4200-150, Porto, Portugal, e-mail: eliana@ufp.edu.pt 
Os polímeros sintéticos são classificados em não-biodegradáveis (por ex., poliestireno, poliacrilamida) e biodegradáveis (por ex., polialquilcianoacrilatos, poliésteres alifáticos $)^{[14]}$. Os polímeros biodegradáveis apresentam vantagens sobre os não-biodegradáveis, pois não necessitam ser removidos cirurgicamente após o término de sua ação ${ }^{[2]}$.

A versatilidade proporcionada pelos polímeros sintéticos permite obter micropartículas com perfis de liberação específicos possibilitando administrar por diversas vias de administração ${ }^{[10,11]}$, como parenteral ${ }^{[15]}$, oral ${ }^{[16]}$ ou oftálmica ${ }^{[17]}$.

\section{Polímeros não-biodegradáveis}

Dentre os polímeros não-biodegradáveis utilizados para a produção de micropartículas destacam-se o poliestireno e a poliacrilamina $^{[12]}$.

O poliestireno é um polímero que origina micropartículas de superfície hidrofóbica, pela polimerização do estireno a temperaturas elevadas $\left(80^{\circ} \mathrm{C}\right)^{[18]}$. As micropartículas de poliestireno são amplamente utilizadas em estudos in vitro e in vivo para explorar o sistema reticuloendotelial (RES). As micropartículas de poliestireno podem ser protegidas da captura do fígado e do baço, através da adsorção de diblocos de co-polímeros anfipáticos à sua superfície, prolongando-se desta forma o seu tempo de residência na corrente sanguínea. $\mathrm{O}$ aumento da hidrofilicidade da superfície do sistema resulta na redução da fagocitose mediada por macrófagos circulantes $^{[19]}$.

Microesferas de poliestireno contendo albumina sérica bovina (BSA) adsorvida à superfície apresentam maior tempo de residência na corrente sanguínea do que as que contêm fibronectina à superfície. Quanto à carga elétrica, a carga positiva parece aumentar a captação e a internalização celular, enquanto a carga negativa reduz a captação ${ }^{[20]}$.

\section{Polímeros biodegradáveis}

Polímeros biodegradáveis e blendas de polímeros biodegradáveis sintéticos são extensamente utilizados na área farmacêutica devido à sua segurança e bicompatibilidade ${ }^{[2]}$.

Os polialquilcianoacrilatos (PACA) são utilizados para a preparação de micropartículas a partir da polimerização aniônica dos cianoacrilatos de alquilo. Devido à presença de dois grupos eletrófilos (cianeto e carboxila) ligados ao carbono, o monômero cianoacrilato de alquila apresenta um caráter dipolar, com uma densidade de carga positiva centrada no átomo de carbono tornando-o susceptível a um ataque nucleófilo, ocorrendo, espontaneamente, a reação de polimerização ${ }^{[5]}$.

Os poliésteres alifáticos caracterizam a classe de polímeros mais extensamente estudada para a preparação de sistemas poliméricos de transporte de princípios ativos. Esta classe de polímeros dizem inclui os poli( $\alpha$-hidroxiácidos), os poli( $\beta$-hidroxiácidos) e a poli( $\varepsilon$ caprolactona). Os poliésteres alifáticos são um grupo de polímeros sintéticos, não-tóxicos e biodegradáveis que, em ambiente aquoso sofrem degradação hidrolítica mediante clivagem de ligações éster originando ácidos hidroxicarboxílicos atóxicos. Estes últimos são metabolizados em dióxido de carbono e água, pela via do ciclo do ácido cítrico ${ }^{[21,22]}$.

Os fatores que influenciam a biodegradação dos poliésteres alifáticos são a composição polimérica (proporção dos ácidos DLláctico e glicólico), a massa molar do polímero, e ainda o $\mathrm{pH}$ e a força iônica do meio ${ }^{[10,11,23]}$.

A superfície das micropartículas pode ser modificada através da adsorção de cadeias hidrófilas, como o PEG, os co-polímeros poli(óxido de propileno)-poli(óxido de etileno) (PPO-PEO) e os diblocos e triblocos de co-polímeros anfipáticos ${ }^{[24]}$.

O PEG e o PEO são polímeros idênticos, diferindo apenas no fato de os grupos metoxi no PEO substituírem os grupos hidroxilo terminais no PEG. O PEG apresenta numerosas vantagens como a elevada solubilidade em água e em solventes orgânicos, biocompatibilidade, ausência de toxicidade e imunogenicidade ${ }^{[25]}$.

\section{Métodos de Produção de Micropartículas}

Existe uma grande variedade de metodologias destinadas à preparação de microsferas e microcápsulas poliméricas sintéticas, que permitem a incorporação de fármacos hidrossolúveis ou lipossolúveis. As principais técnicas empregadas para a veiculação dos princípios ativos incluem emulsificação por extração e/ ou evaporação do solvente ${ }^{[14]}$, coacervação ${ }^{[26-29]}$ e métodos mecânicos ${ }^{[30-32]}$. Para a escolha do método deve-se considerar a simplicidade, reprodutibilidade e exequibilidade do aumento de escala $^{[33]}$.

\section{Emulsificação/Evaporação do Solvente}

A emulsificação/evaporação de solvente é uma das técnicas mais utilizadas na preparação das micropartículas poliméricas sintéticas e permite a incorporação de fármacos hidrossolúveis ou lipossolúveis. Uma vantagem desta metodologia é a sua simplicidade de execução, requerendo apenas a seleção adequada dos solventes, emulsificantes e condições de agitação ${ }^{[14]}$.

\section{Preparação por secagem do meio líquido}

A preparação de micropartículas por secagem no meio líquido corresponde aos métodos baseados na emulsificação por extração e/ou evaporação do solvente do meio das emulsões. Estas podem consistir em emulsões simples - do tipo $\mathrm{O} / \mathrm{A}^{[34,35]}$ ou $\mathrm{O} / \mathrm{O}^{[36,37]}$ ou em emulsões múltiplas do tipo $\mathrm{A} / \mathrm{O} / \mathrm{A}^{[38-40]}$.

A primeira etapa do processo consiste na obtenção da emulsão, na qual uma das fases é constituída por uma solução de um polímero de natureza hidrófobica num solvente adequado. No caso das emulsões do tipo O/A e A/O/A, o polímero está dissolvido num solvente orgânico apolar, como o cloreto de metileno ${ }^{[41]}$ ou clorofórmio $^{[42]}$. No caso das emulsões do tipo $\mathrm{O} / \mathrm{O}$, o solvente do polímero é orgânico polar, por exemplo, o acetonitrila ou acetona ${ }^{[14]}$.

Uma vez preparada a emulsão, procede-se à secagem propriamente dita, isto é, à extração e/ou evaporação do solvente do polímero. A extração consiste na adição à emulsão, sob agitação, de um solvente orgânico miscível com o solvente do polímero e no qual este é insolúvel. Este segundo solvente é denominado solvente de extração, devendo ser miscível com ambas as fases da emulsão. Em alternativa à extração, pode proceder-se unicamente à evaporação. Neste caso, a remoção do solvente do polímero é realizada mantendo-se a emulsão sob agitação, durante um período de tempo suficiente para que o processo ocorra. Como o solvente do polímero apresenta uma certa volatilidade, este é evaporado lentamente da emulsão, sendo acompanhado pela precipitação do polímero e pela formação das micropartículas ${ }^{[3,43,44]}$.

\section{Evaporação e/ou extração do solvente do meio de emulsões do tipo O/A}

A preparação de micropartículas no meio de emulsões do tipo $\mathrm{O} / \mathrm{A}$ origina, via de regra, microsferas ${ }^{[45]}$.

Procede-se inicialmente à dissolução do polímero num solvente orgânico com baixa hidrossolubilidade, como cloreto de metileno ${ }^{[10]}$ ou clorofórmio ${ }^{[45]} \mathrm{e}$, em seguida realiza a dispersão ou dissolução 
do princípio ativo. Se o princípio ativo for hidrossolúvel forma-se emulsões $\mathrm{A} / \mathrm{O} / \mathrm{A}^{[44]}$, se lipossolúvel forma verdadeiras emulsões do tipo $\mathrm{O} / \mathrm{A}^{[46]}$.

Em alguns casos, em particular, para peptídeos e proteínas, podem ser utilizados sistemas de co-solventes para aumentar a solubilidade do princípio ativo na solução polimérica. Quando se recorre a um sistema de co-solventes, utiliza-se como solvente polar o metanol ${ }^{[47]}$ o etanol ${ }^{[47,48]}$ a dimetilformamida ou a $N$-metil2-pirrolidona ${ }^{[49]}$.

A solução orgânica, que constitui a fase interna da emulsão, é então adicionada sob agitação, à uma solução aquosa, contendo um agente tensoativo do tipo O/A, como, por exemplo, o acetato de polivinila (PVA) ${ }^{[10]}$.

Normalmente a preparação da emulsão O/A é realizada à temperatura ambiente $\left(25^{\circ} \mathrm{C}\right)$, embora para determinados princípios ativos se processe a temperaturas inferiores $\left(4-10{ }^{\circ} \mathrm{C}\right)$. Concluída a emulsificação, o sistema mantém-se sob agitação durante um determinado período de tempo, podendo continuar-se por uma das seguintes vias: (i) permitir a difusão lenta do solvente orgânico através da fase externa até à sua evaporação total, conseguindo-se uma precipitação gradual do polímero e formação de microsferas, à medida que o solvente vai sendo eliminado, ou (ii) adicionar à emulsão um solvente de extração, como a acetona, o metanol ou o etanol, o qual facilita a remoção do solvente do polímero, conseguindo-se, desta forma, uma precipitação rápida do mesmo e consequente formação das microsferas ${ }^{[50]}$.

Usualmente a preparação da emulsão $\mathrm{O} / \mathrm{A}$ requer uma velocidade de agitação elevada (5000 a $7000 \mathrm{rpm}$ ), enquanto a remoção do solvente orgânico por evaporação ou por extração processa-se a uma velocidade de agitação menor (500 a $600 \mathrm{rpm}$ ). As microsferas recém-preparadas são separadas por filtração ou por centrifugação. Para remover o agente tensoativo em excesso, as microsferas são lavadas com água deionizada. No final, são sujeitas a secagem, a qual pode realizar-se à temperatura ambiente, sob pressão reduzida ou por liofilização ${ }^{[10]}$.

A Figura 1 apresenta, esquematicamente, o processo de evaporação e/ou extração do solvente orgânico. As microsferas são formadas à medida que o solvente deixa a emulsão, causando a precipitação do polímero e o encapsulação do princípio ativo. Enquanto solvente orgânico estiver presente na emulsão, as microsferas não estão totalmente solidificadas, observando-se um equilíbrio entre o princípio ativo incorporado e não-incorporado, que é tanto maior, quanto maior for a hidrossolubilidade do princípio ativo. As moléculas do princípio ativo não-incorporadas nas microsferas podem estar dissolvidas ou dispersas na fase aquosa ou ainda incluídas nas micelas formadas por moléculas de agente tensoativo em excesso ${ }^{[51]}$.

A emulsificação extração e/ou evaporação do solvente no meio das emulsões do tipo O/A permite, igualmente, a preparação de microcápsulas. Para a preparação de microcápsulas, o princípio ativo é previamente dissolvida em um meio hidrofóbico, como o esqualeno, sendo esta solução adicionada a uma solução do polímero num solvente orgânico apolar. Em seguida, esta fase é emulsificada numa solução aquosa, que contém um agente tensoativo do tipo $\mathrm{O} / \mathrm{A}$, como, por exemplo, o acetato de polivinila (PVA) ${ }^{[32,52]}$.

Após evaporação e/ou extração do solvente do polímero, ocorre a sua precipitação na interface $\mathrm{O} / \mathrm{A}$, com consequente formação das microcápsulas. Estas são recuperadas por filtração, lavadas com $n$-hexano para remover o meio hidrofóbico não-encapsulado e, em seguida, com água deionizada. No final, as microcápsulas são liofilizadas $^{[50,53]}$.

As características fisico-químicas das microsferas e das microcápsulas obtidas por emulsificação extração e/ou evaporação do solvente no meio das emulsões do tipo O/A são afetadas por um conjunto de parâmetros tecnológicos, que incluem a solubilidade do princípio ativo, a natureza e volume das fases interna e externa, a concentração do agente tensoativo, a natureza e concentração do polímero, o volume e a hidrossolubilidade do solvente de extração, a temperatura e a agitação ${ }^{[50,53]}$.

\section{Emulsificação extração e/ou evaporação do solvente do meio das emulsões do tipo 0/0}

A emulsificação extração e/ou evaporação do solvente do meio de emulsões do tipo $\mathrm{O} / \mathrm{O}$ constitui um método particularmente apropriado para incorporar princípios ativos hidrossolúveis em polímeros hidrofóbicos, obtendo-se microsferas ${ }^{[52,54]}$.

Inicialmente, o polímero é dissolvido num solvente orgânico polar, por exemplo, a acetona, o metanol ou a acetonitrila ${ }^{[10,11]}$, constituindo a fase interna, na qual é dissolvida ou dispersa princípios ativos. Em seguida, esta fase é emulsificada na fase externa, constituída por um óleo, como o óleo de semente de algodão ou a parafina líquida, que contém um agente tensoativo do tipo A/O como o estearato de magnésio ou um éster do sorbitano. $\mathrm{O}$ agente tensoativo presente na fase oleosa externa tem por função estabilizar a emulsão do tipo $\mathrm{O} / \mathrm{O}$ e prevenir a agregação das microsferas recém-formadas ${ }^{[10,11,50]}$. Uma vez obtida a emulsão, esta é mantida sob agitação, de modo a permitir a difusão contínua do solvente do polímero para a fase externa oleosa e a sua posterior evaporação. Em alternativa, pode recorrer-se à extração, adicionando-se, sob agitação, à emulsão um solvente de extração, como o éter de petróleo ${ }^{[53]}$.

As microsferas recém preparadas são lavadas com um solvente orgânico como, éter de petróleo, $n$-hexano, ciclohexano ou éter etílico, para eliminar os resíduos de óleo e de agente tensoativo. No final, as microsferas são separadas por filtração, seguindo-se uma lavagem com água deionizada e secagem a pressão reduzida ou por liofilização ${ }^{[32]}$.

\section{Secagem no Meio das Emulsões Múltiplas}

\section{Emulsificação extração e/ou evaporação do solvente do meio de emulsões do tipo $\mathrm{A} / \mathrm{O} / \mathrm{A}$}

A preparação de micropartículas por emulsificação extração e/ou evaporação do solvente do meio de emulsões do tipo A/O/A constitui um método extensamente utilizado para incorporar princípios ativos hidrossolúveis, em particular peptídeos e proteínas ${ }^{[1,55]}$.

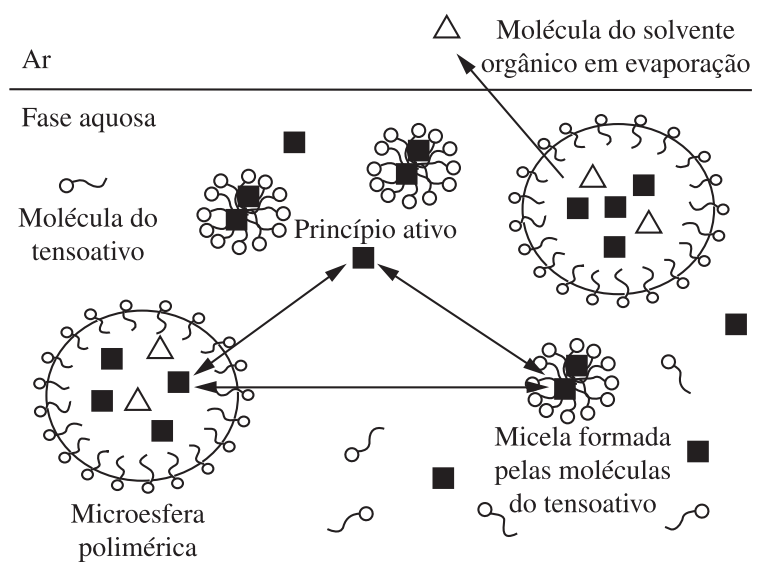

Figura 1. Representação esquemática do processo de evaporação e/ou extração do solvente orgânico. Adaptado de Tse (1999) ${ }^{[51]}$. 
Este método origina microsferas, permitindo a incorporação dos princípios ativos sob a forma de solução aquosa, o que proporciona a sua distribuição homogênea no interior da matriz polimérica ${ }^{[38]}$. O método envolve, previamente, a preparação de uma emulsão primária do tipo $\mathrm{A} / \mathrm{O}$, cuja fase interna é constituída por uma solução aquosa de princípio ativo e a fase externa é constituída por uma solução do polímero num solvente orgânico apolar. Esta solução orgânica pode conter, opcionalmente, um agente tensoativo lipossolúvel como a fosfatidilcolina, o qual favorece a preparação da emulsão A/O. Para estabilizar a emulsão primária pode recorrerse também a proteínas com propriedades tensoativas como a BSA e a ovalbumina, que são incluídas na fase aquosa interna ${ }^{[1,56]}$.

A emulsão primária $\mathrm{A} / \mathrm{O}$ recém preparada é dispersa numa fase aquosa, que contém um agente tensoativo do tipo O/A, como o $\mathrm{PVA}^{[57,58]}$, ou estabilizantes como a polivinilpirrolidona $(\mathrm{PVP})^{[58,59]}$, formando-se a emulsão múltipla A/O/A. Em seguida, procede-se à eliminação do solvente orgânico por extração e/ou evaporação, ocorrendo a precipitação do polímero e a formação das microsferas $^{[58,59]}$.

No final, as microsferas são separadas, lavadas e secas. A separação pode realizar-se por filtração, centrifugação ou ultracentrifugação. A lavagem das microsferas é efetuada com água deionizada ou com uma solução tampão, de modo a eliminar o agente tensoativo. No final, as microsferas são secas a pressão reduzida, a uma temperatura compreendida entre 2 e $8{ }^{\circ} \mathrm{C}$ ou liofilizadas ${ }^{[57]}$.

\section{Coacervação}

Denomina-se coacervação o fenômeno que envolve a dessolvatação de um polímero e a sua separação da respectiva solução polimérica, em duas fases líquidas imiscíveis entre si. Neste processo, uma das fases torna-se mais densa, já que fica relativamente concentrada em polímero, enquanto que a outra fase está praticamente isenta de polímero ${ }^{[26-29]}$.
Este método origina microsferas ${ }^{[60,61]}$ ou microcápsulas ${ }^{[61]}$, quando o princípio ativo se encontra, respectivamente, dispersa sob a forma de partículas sólidas ou dissolvida num óleo imiscível com a solução polimérica.

A dessolvatação do polímero pode ser induzida por alteração da temperatura, por modificação do $\mathrm{pH}$, por adição de um sal, de um "não-solvente" do polímero ou de um polímero incompatível com a solução polimérica ${ }^{[26-29]}$. A Figura 2 apresenta, esquematicamente, o mecanismo de formação das micropartículas por coacervação.

A preparação das micropartículas inicia-se com a obtenção de uma solução polimérica, onde, em seguida, é dispersa a substância activa (Figura 2a). Esta última pode encontrar-se suspensa, sob a forma de partículas finas, ou emulsificada, caso tenha sido previamente dissolvida num óleo imiscível com a solução polimérica ${ }^{[26-29,31]}$.

A coacervação é induzida por um dos procedimentos anteriormente referidos, que provocam a dessolvatação do polímero e a formação de pequenas partículas poliméricas, que se destacam da solução (Figura 2b). Observa-se uma opalescência no sistema, que, ao microscópio, apresenta um aspecto semelhante a uma emulsão. As pequenas partículas poliméricas dessolvatadas depositam-se ou adsorvem-se à volta das gotículas ou partículas de substância ativa a ser incorporada (Figura 2c), e o sistema, que até então se encontrava opalescente, começa a clarificar, à medida que decorre a deposição do polímero. Forma-se uma película fina de coacervado em volta das partículas ou gotículas do principio ativo (Figura 2d). O endurecimento da película de coacervado (Figura 2e) é conseguido por redução da temperatura e adicionando um agente de reticulação ${ }^{[26-29,31]}$.

No final, as micropartículas são separadas por decantação, filtração ou centrifugação e lavadas com água deionizada ou com uma solução tampão, usando-se esta última caso ocorra a perda de princípio ativo das micropartículas por lavagem com água desionizada. A secagem pode realizar-se a pressão reduzida ou por liofilização. A coacervação realiza-se em meio aquoso, quando se recorre a polímeros hidrossolúveis e em meio não aquoso, quando se recorre a polímeros lipossolúveis ${ }^{[26-29,31]}$.

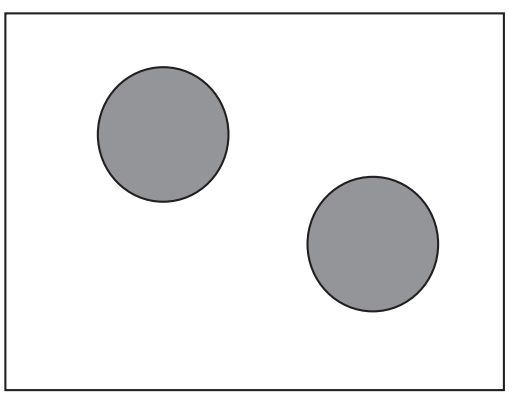

(1)

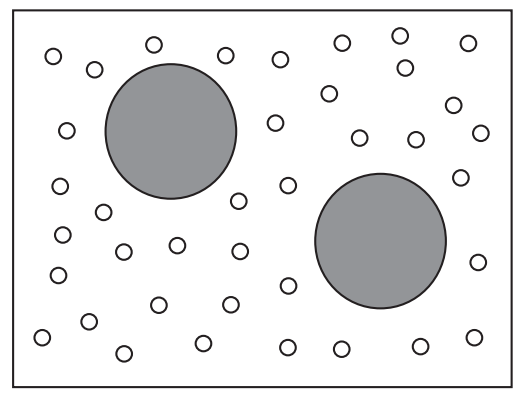

(2)

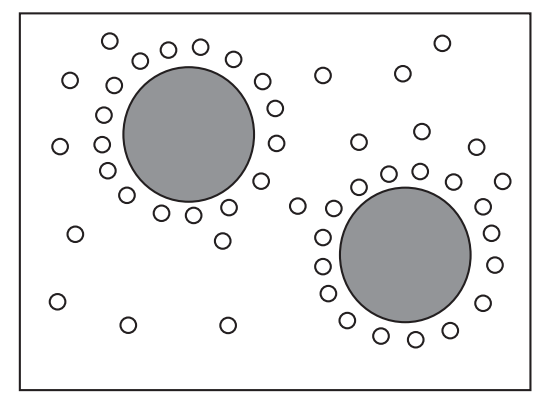

(3)

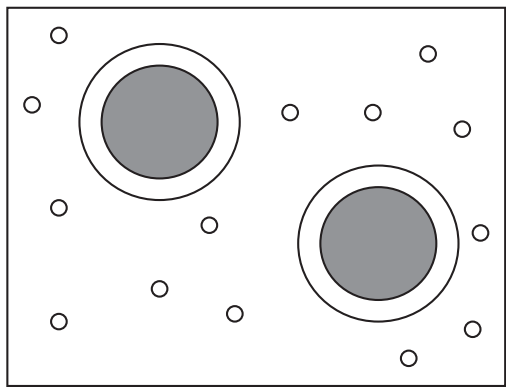

(4)

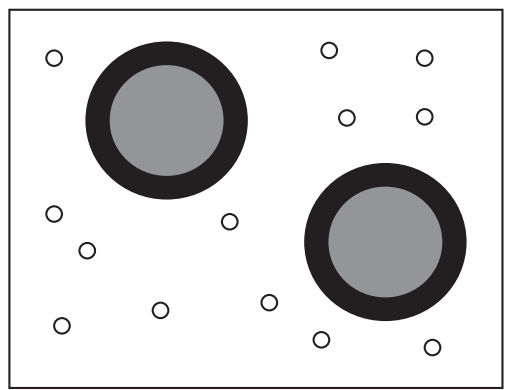

(5)

Figura 2. Representação esquemática do mecanismo de formação de micropartículas por coacervação. Adaptado de Jyothi et al. ${ }^{[31]}$. 


\section{Coacervação em meio não-aquoso}

A coacervação em meio não-aquoso destina-se à incorporação de substâncias ativas hidrofílicas, em microsferas formadas por polímeros hidrófobicos, como os poliésteres alifáticos ${ }^{[61]}$.

O método consiste na dissolução prévia do polímero num solvente orgânico de natureza apolar como o cloreto de metileno, o clorofórmio, o acetato de etila, ou o tolueno, seguindo-se a indução da coacervação por alteração da temperatura, por adição de um "não-solvente" ou de um polímero incompatível ${ }^{[32]}$.

\section{Coacervação por alteração da temperatura}

A coacervação induzida por alteração da temperatura requer que o polímero seja solúvel no solvente orgânico a uma temperatura superior à temperatura ambiente e insolúvel abaixo desta última. $\mathrm{O}$ método consiste na preparação prévia de uma solução polimérica num solvente adequado, a uma temperatura elevada, na qual se dispersa o princípio ativo. Devido à insolubilidade do polímero no solvente orgânico à temperatura ambiente, ao ocorrer o arrefecimento o polímero precipita e aprisiona a substância ativa. Por razões óbvias, este método somente é aplicável em princípios ativos termoestáveis ${ }^{[62]}$.

\section{Coacervação por adição de um "não-solvente"}

A coacervação por adição de um "não-solvente" consiste na adição, a uma solução polimérica que contém em suspensão a substância activa a incorporar, de um solvente orgânico que provoca a dessolvatação do polímero formador das micropartículas. São exemplos de "não-solventes" a acetona, o éter dietílico, o etanol, o metanol e o $n$-hexano ${ }^{[61]}$.

Com a finalidade de solidificar as microsferas recém-preparadas, estas são lavadas com um volume elevado do "não-solvente"[61]. No final, são separadas, lavadas com água desionizada e liofilizadas. Owusu-Ababio et al. ${ }^{[63]}$ incorporaram ciprofloxacina em microsferas de L-PLA por este método. A quinolona foi dispersa numa solução de polímero em cloreto de metileno e a coacervação foi induzida pelo éter dietílico.

\section{Coacervação por adição de um polímero incompativel}

A coacervação por adição de um polímero incompatível consiste na adição, a uma solução polimérica que contém em suspensão o princípio ativo a ser incorporado, de um polímero incompatível com o polímero formador das micropartículas ${ }^{[61]}$.

À medida que se adiciona o polímero incompatível, o polímero formador das micropartículas destaca-se da solução e deposita-se à volta do princípio ativo que se encontra dispersa. Um exemplo de polímeros incompatíveis é o óleo de silicone.

As microsferas recém-preparadas são posteriormente endurecidas com $n$-hexano, octametilciclotetrasiloxano (OMCTS) ou com heptano ${ }^{[64,65]}$.

\section{Métodos Mecânicos}

A preparação de micropartículas por métodos mecânicos baseiase na utilização de dispositivos injetores, estacionários ou giratórios, podendo realizar-se por atomização ${ }^{[30]}$, fusão $0^{[31]}$ ou fluidização ${ }^{[32]}$.

\section{Atomização}

O processo de atomização, também conhecido por spray-drying, comparado com os outro métodos proporciona várias vantagens como boa reprodutibilidade, maior controle do tamanho da micropartícula, e é menos dependente da solubilidade do princípio ativo no polímero ${ }^{[66]}$.
Inicia-se com a dissolução prévia de um polímero de natureza lipofílica, como o PLGA num solvente adequado ${ }^{[67]}$. Em seguida, o princípio ativo é dissolvido ou disperso na solução polimérica, a qual, por sua vez, é atomizada numa câmara de secagem ${ }^{[30]}$.

Quando o princípio ativo é dissolvido ou suspenso na solução polimérica o processo conduz à obtenção de microsferas. Quando a substância é emulsificada na solução polimérica são obtidas microcápsulas ${ }^{[67]}$.

\section{Fusão}

Este método de preparação de micropartículas também é denominado spray-congealing ${ }^{[31]}$. Baseia-se na transformação de gotículas do polímero fundido em micropartículas sólidas por congelamento.

Neste método, o polímeroé previamente submetido a um processo de fusão, seguindo-se a dissolução ou dispersão do princípio ativo na massa fundida. Esta é posteriormente atomizada numa câmara, na qual circula uma corrente de ar frio ou um gás previamente arrefecido. Trata-se de um método que, tal como a atomização, ocorre numa única fase, apresentando o inconveniente de se limitar a polímeros e dispersão do princípio ativo termoestáveis ${ }^{[32]}$.

\section{Fluidização}

A preparação de micropartículas por fluidização, também denominada por revestimento por suspensão no ar ou em leito fluido, baseia-se na utilização de uma câmara de Würster, na qual circula uma corrente de ar quente ${ }^{[32]}$. Esse método é muito útil para a encapsulação de princípios ativos hidrofóbicos ${ }^{[68]} \mathrm{e}$, particularmente, para a produção em grande escala ${ }^{[32]}$. Também é escalonável e paresenta boa reprodutibilidade ${ }^{[69]}$.

O método envolve a preparação prévia de uma solução do polímero num solvente adequado, a qual é atomizada numa câmara, onde as partículas dispersão do princípio ativo encontram em suspensão numa corrente de ar quente. A solução de polímero é lançada sobre as partículas dispersão do princípio ativo, originando microsferas após a evaporação do solvente do polímero ${ }^{[69]}$.

A colisão das microsferas no interior da câmara de Wurster contribui para a redução das suas dimensões e para o alisamento da sua superfície. O maior inconveniente deste método reside na dificuldade em revestir partículas de substâncias de dimensões reduzidas. Com efeito, as partículas de menor tamanho susceptíveis de serem revestidas pela solução polimérica, sem ocorrer aglomeração, é de cerca de $20 \mu \mathrm{m}$. Apesar de tudo, este processo origina uma aglomeração elevada, mesmo para partículas de dimensões compreendidas entre 20 e $100 \mu \mathrm{m}$, dependendo da sua higroscopicidade e carga electrostática responsáveis, pela formação incompleta do filme de revestimento ${ }^{[70]}$.

\section{Preparação através do sistema de extração de solvente por aerossol}

A preparação de micropartículas através do sistema de extração do solvente por aerossol (ASES, aerosol solvent extraction system) foi desenvolvido por Bleich et al. ${ }^{[71]}$ e permite a obtenção de microsferas a partir de soluções poliméricas, através da utilização de um fluido supercrítico ${ }^{[32]}$.

O processo consiste na atomização, num fluido supercrítico, de uma solução polimérica num solvente orgânico adequado, na qual é dissolvida ou dispersa dispersão o princípio ativo. Enquanto que o solvente orgânico é solúvel no fluido supercrítico e é extraído durante o processo a uma corrente constante, o polímero é insolúvel nessa fase, pelo que precipita, incorporando o princípio ativo e formando as microsferas ${ }^{[72,73]}$. 
$\mathrm{O} \mathrm{CO}_{2}$ é um dos fluidos supercríticos mais utilizados devido ao seu valor reduzido de temperatura e pressão críticas $\left(T_{\mathrm{c}}=31,1{ }^{\circ} \mathrm{C}\right.$; $P_{\mathrm{c}}=73,8 \mathrm{bar}$ ), tornando-se atrativo para processar substâncias termossensíveis. Além disso, o $\mathrm{CO}_{2}$ é atóxico, não inflamável, pouco dispendioso, aceitável do ponto de vista ambiental e tem um poder de solvatação relativamente elevado quando comparado com outros fluidos supercríticos ${ }^{[74,75]}$.

Há dois motivos que justificam a preparação de microsferas através do ASES. O primeiro diz respeito ao poder de solvatação seletivo do fluido supercrítico, que torna possível a separação de um componente particular de uma mistura complexa. Tal deve-se a pequenas alterações da pressão ou da temperatura próximas do ponto crítico, que modificam a densidade do fluido supercrítico. $\mathrm{O}$ segundo deve-se ao fato dos gases envolvidos no processo poderem ser reciclados, o que se torna vantajoso sob o ponto de vista econômico e ambiental. Além disso, trata-se de um processo de uma única etapa, reprodutível à escala industrial. Este processo permite trabalhar em condições assépticas e não requer procedimentos adicionais de secagem para a remoção do solvente orgânico ${ }^{[76]}$.

\section{Conclusão}

O uso de polímeros sintéticos ou semi-sintéticos biodegradáveis na produção de micropartículas (ou mais recentemente nanopartículas) é uma aplicação consolidada na área médica e farmacêutica. A grande variedade de tecnologias de produção aliada ao grande e crescente número de polímeros disponíveis, o que faz ser possível a incorporação de ativos hidrofílicos ou hidrofóbicos, faz esta abordagem ser sempre considerada como uma boa opção para aplicações de drug delivery e liberação controlada, especialmente em aplicações mais nobres como, por exemplo, microencapsulação de diversas proteínas e peptídeos, bem como ativos quimioterápicos e vacinas.

\section{Agradecimentos}

Os autores agradecem à Fundação para a Ciência e a Tecnologia (FCT) do Ministério da Ciência e Tecnologia (PTDC/SAUFAR/113100/2009), à Fundação de Amparo à Pesquisa do Estado de São Paulo (FAPESP/Brasil) e à Coordenação de Aperfeiçoamento de Pessoal de Nível Superior (Capes, Brasil).

\section{Referências Bibliográficas}

1. Odonnell, P. B.; \& McGinity J. W. - Adv. Drug Deliv. Rev., 28, p.25 (1997).

2. Brannonpeppas, L. - Int. J. of Pharm., 116, p.1 (1995).

3. Yoo, J. W.; Lee, J. S. \& Lee, C. H. - J Biomed Mater Res A, 92A, p.1233 (2010).

4. Patil, S. B. \& Sawant, K.K.- Cur. Drug Deliv., 5, p.312 (2008). http:// dx.doi.org/10.2174/156720108785914970

5. Delie, F. \& Blanco-Prieto, M. J. - Molecules, 10, p.65 (2005). http:// dx.doi.org/10.3390/10010065

6. Freiberg, S. \& Zhu, X.- Int. J. Pharm., 282, p.1 (2004). http://dx.doi. org/10.1016/j.ijpharm.2004.04.013

7. Shahani, K.; Swaminathan, S. K.; Freeman, D.; Blum, A.; Ma, L. A. \& Panyam J. - Cancer Res., 70, p.4443 (2010). http://dx.doi. org/10.1158/0008-5472.CAN-09-4362

8. Lopez-Donaire, M. L.; Fernandez-Gutierrez, M.; Parra-Caceres, J.; Vázquez-Lasa, B.;García-Alvarez, I.; Fernández-Mayoralas, A. \& Román, J. S. - Acta Biomater., 6, p.1360 (2010).

9. Cruz, L.; Assumpção, E. \& Andrade, S. F. - Eur J Pharm Sci, 40, p. 441 (2010). http://dx.doi.org/10.1016/j.ejps.2010.05.001
10. Jain, R. A. - Biomaterials, 21, p.2475 (2000). http://dx.doi.org/10.1016/ S0142-9612(00)00115-0

11. Jain, R. A.; Rhodes, C. T.; Railkar, A. M.; Malick, A. W.; Shah, N. H. - Eur J Pharm Biopharm., 50, p.257 (2000). http://dx.doi.org/10.1016/ S0939-6411(00)00062-X

12. Pillai, O. \& Panchagnula, R. -. Curr. Opin. Chem. Biol., 5, p.447 (2001). http://dx.doi.org/10.1016/S1367-5931(00)00227-1

13. Qiu, L. Y. \& Bae, Y. H. - Pharm. Res., 23, p.1 (2006). http://dx.doi. org/10.1007/s11095-005-9046-2

14. Li, M.; Rouaud, O. \& Poncelet, D. - Int. J. Pharm., 363, p.26 (2008). http://dx.doi.org/10.1016/j.ijpharm.2008.07.018

15. Kranz, H.; Yilmaz, E.; Brazeau, G. A. \& Bodmeier, R. - Pharm. Res., 25, p.1347 (2008). http://dx.doi.org/10.1007/s11095-007-9478-y

16. Khan, F.; Katara, R. \& Ramteke S. - AAPS Pharm. Sci. Tech., 11, p.1368 (2010). http://dx.doi.org/10.1208/s12249-010-9505-X

17. Tong, Y. C.; Chang, S. F.; Liu, C.Y.; Kao, W.W.; Huang, C.H. \& Liaw, J. - J. Gene. Med., 9, p.956 (2007). http://dx.doi.org/10.1002/jgm.1093

18. Lok, K. P. \& Ober, C. K. - Can. J. Chem., 63, p.209 (1985). http://dx.doi.org/10.1139/v85-033

19. Dunn, S. E.; Brindley, A.; Davis, S. S.; Davies, M. C. \& Illum, L. - Pharm. Res., 11, p.1016 (1994). http://dx.doi.org/10.1023/A:1018939521589

20. Tabata, Y. \& Ikada, Y. - Adv. Polym. Sci., 94, p.107 (1990). http://dx.doi.org/10.1007/BFb0043062

21. Reed, A. M. \& Gilding, D. K. - Polymer, 22, p.494 (1981). http://dx.doi.org/10.1016/0032-3861(81)90168-3

22. Nair, L. S. \& Laurencin, C. T. - Prog. Polym. Sci., 32, p.762 (2007). http://dx.doi.org/10.1016/j.progpolymsci.2007.05.017

23. Jiang, W. L. \& Gupta, R. K. - Adv. Drug Deliv. Rev., 57, p.391 (2005). http://dx.doi.org/10.1016/j.addr.2004.09.003

24. Luck, M.; Pistel, K. F.; Li, Y. X.; Blunk, T.; Muller, R. H. \& Kissel, T. - J. Control. Release., 55, p.107 (1998). http://dx.doi.org/10.1016/ S0168-3659(98)00030-3

25. Wattendorf, U. \& Merkle, H. P. - J. Pharm. Sci., 97, p.4655 (2008). http://dx.doi.org/10.1002/jps.21350

26. Nihant, N.; Grandfils, C.; Jerome, R. \& Teyssie, P. - J. Control. Release., 35, p.117 (1995). http://dx.doi.org/10.1016/01683659(95)00026-5

27. Nihant, N.; Stassen, S.; Grandfils, C.; Jerome, R. \& Teyssie, P. - Polym. Int., 32, p.171 (1993). http://dx.doi.org/10.1002/pi.4990320210

28. Nihant, N.; Stassen, S.; Grandfils, C.; Jerome, R.; Teyssie, P. \& Goffinet, G. - Polym. Int., 34, p.289 (1994). http://dx.doi.org/10.1002/ pi.1994.210340308

29. Stassen, S.; Nihant, N.; Martin, V.; Grandfils, C.; Jerome, R. \& Teyssie, P. - Polymer, 35, p.777 (1994). http://dx.doi.org/10.1016/00323861(94)90876-1

30. Re, M. I. - Drying Technol., 16, p.1195 (1998).

31. Jyothi, N. V. N.; Prasanna, P. M.; Sakarkar, S. N.; Prabha, K. S.; Ramaiah, P. S. \& Srawan, G. Y. - J. Microencapsul., 27, p.187 (2010). http://dx.doi.org/10.3109/02652040903131301

32. Wischke, C. \& Schwendeman, S. P. - Int. J. Pharm., 364, p.298 (2008). http://dx.doi.org/10.1016/j.ijpharm.2008.04.042

33. Yang, L. \& Alexandridis, P. - Cur. Opin. Colloid \& Interface Sci., 5, p.132 (2000). http://dx.doi.org/10.1016/S1359-0294(00)00046-7

34. Kietzmann, D.; Beduneau, A.; Pellequer, Y. \& Lamprecht, A. - Int. J. Pharm., 375, p.61 (2009). http://dx.doi.org/10.1016/j. ijpharm.2009.04.006

35. Furtado, S.; Abramson, D.; Simhkay, L.; Wobbekind, D. \& Mathlowitz, E. - Eur. J. Pharm. Biopharm., 63, p.229 (2006). http://dx.doi. org/10.1016/j.ejpb.2005.12.012 
36. Mana, Z.; Pellequer, Y. \& Lamprecht, A. - Int. J. Pharm., 338, p.231 (2007). http://dx.doi.org/10.1016/j.ijpharm.2007.02.010

37. Viswanathan, N. B.; Thomas, P. A.; Pandit, J. K.; Kulkarni, M. G. \& Mashelkar, R. A. - J. Control. Release, 58, p.9 (1999). http://dx.doi. org/10.1016/S0168-3659(98)00140-0

38. Klose, D.; Siepmann, F.; Willart, J. F.; Descamps, M. \& Siepmann, J. - Int. J. Pharm., 383, p.123 (2010). http://dx.doi.org/10.1016/j. ijpharm.2009.09.012

39. Nihant, N.; Schugens, C.; Grandfils, C.; Jerome, R. \& Teyssie, P. - Pharm. Res., 11, p.1479 (1994). http://dx.doi.org/10.1023/A:1018912426983

40. Feng, L.; Qi, M. R.; Zhou, X. J.; Maitani, Y.; Wang, S. C.;Jiang, Y. \& Nagai, T. - J. Control. Release, 112, p.35 (2006). http://dx.doi. org/10.1016/j.jconrel.2006.01.012

41. Jelvehgari, M.; Barar, J.; Valizadeh, H. \& Heidari, N. - Iran. J. Basic Med. Sci., 13, p.85 (2010).

42. Ito, F.; Fujimori, H.; Honnami, H.; Kawakami, H.; Kanamura, K. \& Makino, K. - Eur Polymer J., 45, p.658 (2009). http://dx.doi. org/10.1016/j.eurpolymj.2008.12.037

43. Lassalle, V. \& Ferreira, M. L. -. Macromol. Biosci., 7, p.767 (2007). http://dx.doi.org/10.1002/mabi.200700022

44. Ito, F.; Fujimori, H.; Honnami, H.; Kawakami, H.; Kanamura, K. \& Makino, K. - J. Mater. Sci. Mater. Med., 21, p.1563 (2010). http://dx.doi.org/10.1007/s10856-010-3995-7

45. Sinha, V. R. \& Trehan, A. - Drug Deliv., 12, p.133 (2005). http://dx.doi. org/10.1080/10717540590925726

46. Hammady, T.; El-Gindy, A.; Lejmi, E.; Dhanikula, R. S.; Moreau, P. \& Hildgen, P. - Int. J. Pharm., 369, p.185 (2009). http://dx.doi. org/10.1016/j.ijpharm.2008.10.034

47. Jovanovic, I.; Jordovic, B.; Petkovic, M.; Ingnjatovic, N. \& Uskokovic, D. - Microsc. Res. Tech., 71, p.86 (2008).

48. Rawat, A. \& Burgess, D.J. - Int. J. Pharm., 394, p.99 (2010). http:// dx.doi.org/10.1016/j.ijpharm.2010.05.013

49. Wang, Y.; Guo, B. H.; Wan, X.; Xu, J.; Wang, X. \& Zhang, Y. P.- Polymer, 50, p.3361 (2009). http://dx.doi.org/10.1016/j. polymer.2009.03.061

50. Arshady R. - J. Control. Release, 17, p.1 (1991). http://dx.doi. org/10.1016/0168-3659(91)90126-X

51. Tse, G.; Blankschtein, D.; Shefer, A. \& Shefer, S. - J. Control. Release, 60, p.77 (1999). http://dx.doi.org/10.1016/S01683659(99)00056-5

52. Rungseevijitprapa, W. \& Bodmeier, R. - Eur. J. Pharm. Sci., 36, p.524 (2009). http://dx.doi.org/10.1016/j.ejps.2008.12.003

53. Jalil, R. \& Nixon, J. R. - J. Microencapsul., 7, p.297 (1990). http:// dx.doi.org/10.3109/02652049009021842

54. Mahdavi, H.; Mirzadeh, H.; Hamishehkar, H., Jamshidi, A.; Fakhari, A.; Emami, J.; Najafabadi, A. R.; Gilani, K.; MInaiyan, M.; Najafi, M.; Tajarod, M. \& Nokhodchi, A. - J. Appl. Polym. Sci., 116, p.528 (2010). http://dx.doi.org/10.1016/j.jconrel.2010.05.026

55. Lee, J.; Oh, Y. J.; Lee, S. K \& Lee, K. Y.- J. Control. Release, 146, p.61 (2010). http://dx.doi.org/10.1016/j.jconrel.2010.05.026

56. Soriano, I.; Delgado, A.; Diaz, R. V. \& Evora, C. Drug Dev. Ind. Pharm., 21, p.549 (1995). http://dx.doi. org/10.3109/03639049509048122
57. Chaisri, W.; Hennink, W. E.; Ampasavate, C. \& Okonogi, S. - Aaps Pharmscitech., 11, p.945 (2010). http://dx.doi.org/10.1208/s12249010-9453-5

58. Coombes, A. G. A.; Yeh, M. K.; Lavelle, E. C. \& Davis, S. S. - J. Control. Release, 52, p.311 (1998). http://dx.doi.org/10.1016/S01683659(98)00006-6

59. Bezemer, J. M.; Radersma, R.; Grijpma, D. W.; Dijkstra, P.J.; Van Blitterswijk, C. A. \& Feijen, J. - J. Control. Release, 67, p.233 (2000). http://dx.doi.org/10.1016/S0168-3659(00)00213-3

60. Mallarde, D.; Boutignon, F, Moine, F.;Barré, E.; David, S.; Touchet, H.; Ferruti, P. \& Deghenghi, R. - Int. J. Pharm., 261, p.69 (2003).

61. Arshady R. - Polymer Engineering Sci., 30, p.905 (1990). http://dx.doi. org/10.1002/pen.760301505

62. Sugihara, S.; Ohashi, M. \& Ikeda, I. - Macromolecules, 40, p.3394 (2007). http://dx.doi.org/10.1021/ma062365v

63. OwusuAbabio, G. \& Rogers, J.A. - J. Microencapsul., 13, p.195 (1996).

64. Thomasin, C.; Ho, N. T.; Merkle, H. P. \& Gander, B.- J. Pharm. Sci., 87, p.259 (1998). http://dx.doi.org/10.1021/js970047r

65. Thomasin, C.; Merkle, H. P. \& Gander, B. - J. Pharm. Sci., 87, p.269 (1998). http://dx.doi.org/10.1021/js970048j

66. Park, J. H.; Ye, M. L. \& Park, K. - Molecules, 10, p.146 (2005). http:// dx.doi.org/10.3390/10010146

67. Van de Weert, M.; Hennink, W. E. \& Jiskoot, W. - Pharm. Res., 17, p.1159 (2000). http://dx.doi.org/10.1023/A:1026498209874

68. Mu, L.; Teo, M. M.; Ning, H. Z.; Tan, C. S. \& Feng, S. S. - J. Control. Release, 103, p.565 (2005). http://dx.doi.org/10.1016/j. jconrel.2004.12.023

69. Shi, S. A. \& Hickey, A. J. - Pharm. Res., 27, p.350 (2010). http://dx.doi. org/10.1007/s11095-009-0028-7

70. Perera, G.; Barthelmes, J. \& Bernkop-Schnurch, A. - J. Control. Release, $\quad \mathbf{1 4 5}, \quad$ p.240 (2010). http://dx.doi.org/10.1016/j. jconrel.2010.04.024

71. Bleich, J.; Muller, B. W. \& Wassmus, W. - Int. J. Pharm., 97, p.111 (1993). http://dx.doi.org/10.1016/0378-5173(93)90131-X

72. Varughese, P.; Li, J.; Wang, W. \& Winstead, D. - Powder Technology, 201, p.64 (2010). http://dx.doi.org/10.1016/j.powtec.2010.03.008

73. Bleich, J. \& Muller, B.W. J. Microencapsul., 13, p.131 (1996). http:// dx.doi.org/10.3109/02652049609052902

74. Hezave, A. Z.; Aftab, S. \& Esmaeilzadeh, F. - J. Aerosol Sci., 41, p.821 (2010). http://dx.doi.org/10.1016/j.jaerosci.2010.01.006

75. Ginty, P. J.; Whitaker, M. J.; Shakesheff, K. M. \& Howdle, S. M. Materials Today, 8, p.42 (2005). http://dx.doi.org/10.1016/S13697021(05)71036-1

76. Vatanara, A.; Najafabadi, A. R.; Khajeh, M. \& Yamini, Y. - J. Supercrit. Fluids, 33, p.21 (2005).

Enviado: 08/10/10

Reenviado: 08/12/10

Aceito: $24 / 02 / 11$

DOI: $10.1590 / \mathrm{S} 0104-14282011005000060$ 